\title{
Study on Fatigue Property of Cracked Steel Plate Strengthened by CFRP
}

\author{
Xi-Zhi Wu ${ }^{1,2}$, Wei-Kang Yang ${ }^{3}$, Xian-Guo Zang ${ }^{1}$ \\ ${ }^{1}$ College of Materials Science and Engineering, Central South University of Forestry and Technology, China,410082 \\ ${ }^{2}$ Yihua Life Science and Technology Co., Ltd. Guangdong,China,515000 \\ ${ }^{3}$ Guangzhou Automobile Group Co., Ltd Research and Design Center, Guangdong, China, 510000
}

\begin{abstract}
This paper presents fatigue property of CFRP-strengthened cracked steel plate. Firstly, the finite element model of CFRP-strengthened cracked steel plate is established by using the cohesive zone model. With the finite element model, stress intensity factor of the crack-tip is calculated. Then, it gives the fatigue tests of cracked steel plate. According to the experimental data, the material constants $C$ and $n$ values are obtained. The prediction fatigue life is calculated by the finite element model and Paris function and verified by the experimental data. The results show that the prediction fatigue life, calculated by the finite element model and the Paris formula, is consistent with the experimental fatigue life, which verifies the accuracy of our prediction model with finite element model and the Paris function.
\end{abstract}

Key words: Composite materials; Crack; CFRP; Fatigue; Repair;

\section{Introduction}

Cracks may occur on the material of steel structure or around weld after running a period of time. Fatigue crack is known as a critical attribute to deteriorate steel structure, including progressive crack propagation [1]. Timely rehabilitation can avoid the fatal failure of the damaged system. Many recent research shows that carbon fiber reinforced polymer (CFRP) is a promising material to strengthen constructed steel structures [2-4].

While many recent research focuses on the static performance of steel structures strengthened with CFRP[5-7], there are relatively few works on the study of fatigue performance. Jones [8] studied the four-point bending fatigue test of I-shaped beams strengthened with CFRP. The results show that, when the stress amplitude is $207 \mathrm{MPa}$ and 345 $\mathrm{MPa}$, the fatigue life of beams strengthened with CFRP is increased 3.4 times and 2.6 times respectively, compared with the unreinforced beams. Hui Jiao [9] investigated the fatigue behaviour of defect steel beams retrofitted with three different methods, i.e., welding, welding and bonding with CFRP plates or CFRP woven sheets laminated via a wet lay-up process. It was found that the fatigue life was extended abound 3 times for beams strengthened with 4 layers of CFRP woven sheets. Mean S-N curves were obtained based on the test data, that can be used to predict the fatigue life of steel beams retrofitted with similar CFRP materials. Amer [10] presented the crack-tip behavior of wide-flange steel beams 
strengthened with carbon fiber reinforced polymer (CFRP) sheets. Three-dimensional finite element models were developed to predict stress singularity at the crack-tip, including an adaptive mesh formulation along with isoperimetric quadratic elements. The stress intensity of the damaged (notched) beams was reduced with the presence of the CFRP, which generated a crack-bridging effect. Zhang [11] established the finite element model on the stress intensity factor of surface crack with the help of ANSYS. Based on this model, the effects of carbon fiber layer(CFL )thickness, crack shape ratio and crack area on the stress intensity factor were analyzed for the strengthened steel plate under bending load. The results show that CFL strengthening greatly decreases the stress intensity factor of surface crack in the steel structure. Yang [12] studied on cracked aluminum alloy plate strengthened with CFRP by experiment. In this paper, breaking strength is increased by $34.28 \%$ and the fatigue life is increased by 2.06 times, when compared with unrepaired cracks aluminum alloy plate.

From the above illustration, these papers verify CFRP-strengthening can improve the fatigue life of cracked steel structure from the stress intensity factor or test. However, in the application of CFRP strengthening cracked steel structure, it is necessary to predict the fatigue life of CFRP- strengthened cracked steel structure. Currently, there is little literature studying on prediction of the fatigue life of CFRP reinforcement cracked steel structure. In this paper, The Paris function is adopted to predict the fatigue life of cracked steel plate strengthened by CFRP. It establishes the finite element model of CFRP-strengthened cracked steel plate by using the cohesive zone model. With the finite element model, the stress intensity factor of cracked steel plate is calculated. Then, the fatigue tests of cracked steel plate are completed for calculating material constants $C$ and $n$ and verifying the predicting fatigue life.

\section{Prediction method for fatigue life of cracked steel plates}

According to the mechanism of fatigue fracture, the fatigue life of steel structure is composed of crack initiation life and crack propagation life. If a steel structure has initial fatigue crack, its fatigue life is determined by the crack propagation life. Linear elastic fracture mechanics (LEFM) is usually adopted to describe crack behavior [13]. According to LEFM, the stress intensity factor of crack-tip is an important parameter for the crack growth rate, and the famous description of its relation is the Paris-Erdogan model [14]:

$$
d a / d N=C\left(\Delta K_{I}\right)^{n}
$$

Where $C$ and $n$ are the material constant, $\Delta K_{I}$ is the range of stress intensity factor, $a$ is the crack length, and $N$ is the number of fatigue cycles.

It's assumed that the value of parameters $C$ and $n$ are unchanged before and after steel plates strengthened, and Eq. (1) is proposed by integral:

$$
N=\frac{1}{C} \int_{a_{1}}^{a_{2}} \frac{d a}{\left(\Delta K_{I}\right)^{n}}
$$

Where $a_{1}$ is the length of initial crack, $a_{2}$ is the length of final crack, and $N$ is the number of fatigue cycles from the initial crack length to the final crack length.

Through the above illustration, it is found that the key factor is to calculate the stress intensity factor amplitude $\Delta K_{I}$ and material constants $C$ and $n$ for the prediction of fatigue life. For simple steel plate without CFRP reinforcement, $\Delta K_{I}$ can be solved through analytic method [15]. However, for CFRP strengthened steel plate, it has to be calculated by finite element 
method. Material constants $C$ and $n$ can be obtained using Eq. (1) by the experimental data and $\Delta K_{I}$.

\section{Stress intensity factor calculation}

According to Eq. (2) for predicting the fatigue life of CFRP-strengthened cracked steel plate, the range of stress intensity factor $\Delta K_{I}$ is an important parameter. For CFRP strengthened steel plate, it has to be calculated by finite element method. The finite element model of CFRP-strengthened cracked steel plate is established by using the cohesive zone model. To validate the finite element model, the stress intensity factor value of bare cracked steel plates, calculated by the finite element model, is compared with the stress intensity factor value calculated by analytic method. With the finite element model of CFRP-strengthened cracked steel plate, stress intensity factor of the crack can be calculated.

\subsection{Cohesive zone model}

The cohesive zone model is essentially the interaction force between the physical atoms or molecules, and defines a function of the interface opening displacement and the cohesive force on imaginary surface of the cohesive area. Generally, normal cohesive force and tangential cohesive force won't exist coupling relationship, which is that normal displacement won't cause tangential cohesive force and tangential sliding won't cause normal cohesive force. The constitutive relation of the cohesive force is given as follows:

$$
t=\left\{\begin{array}{l}
t_{n} \\
t_{s} \\
t_{t}
\end{array}\right\}=\left[\begin{array}{ccc}
K_{\mathrm{nn}} & 0 & 0 \\
0 & K_{s s} & 0 \\
0 & 0 & K_{t t}
\end{array}\right]\left\{\begin{array}{l}
\delta_{n} \\
\delta_{s} \\
\delta_{t}
\end{array}\right\}=K \delta
$$

The following symbols are used in this formula:

$t$, cohesive force vector; $t_{n} 、 t_{s} 、 t_{t}$, normal component and two tangential components of the cohesive force vector;

$\delta$, interface opening displacement;

$\delta_{n} 、 \delta_{s} 、 \delta_{t}$, normal component and two tangential components of the interface opening displacement;

$K$, interface stiffness;

$K_{n n} 、 K_{s s} 、 K_{t t}$, normal component and two tangential components of the interface stiffness.

With the increase of load, interface will be softened. Bilinear tension displacement method is the most common way to describe interface softening phenomenon. Bilinear law is shown in Fig.1, abscissa represents the opening displacement of the interface, ordinate represents the cohesive force of the interface, $t_{\max }$ is the interface strength, $\delta_{\text {eq.o }}$ is the opening displacement corresponding to the interface strength, and $\delta_{\text {eq.f }}$ is the opening displacement corresponding to the interface cracking. When the external load acts on the interface, the cohesive force of interface increases linearly; when the cohesive force reaches the interface strength, cohesive force gradually reduces to zero and then it corresponds to the interface crack displacement. Introducing a variable $n=\max \left(\delta_{e q}\right)$ which represents the maximum displacement in loading history, then the bilinear law can be expressed as

$$
t_{e q}= \begin{cases}T_{e} \delta_{e q} & \delta_{e q} \leq \delta_{e q .0} \\ \frac{\delta_{e q . f}-\delta_{e q}}{\delta_{e q . f}-\delta_{e q .0}} t_{\max } & \delta_{e q} \geq n \\ \left(1-\frac{\delta_{e q . f}\left(n-\delta_{e q .0}\right)}{n\left(\delta_{e q . f}-\delta_{e q .0}\right)}\right) T_{e} \delta_{e q} & \delta_{e q .0} \leq \delta_{e q}<n\end{cases}
$$




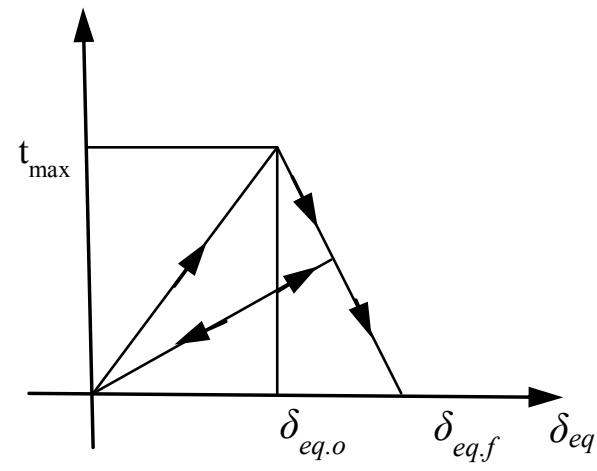

Fig.1 Bilinear law of cohesive zone model

\subsection{Finite element model}

It's a multi-layer composite structure for CFRP strengthened steel plate, including steel, adhesive layer and CFRP. Since the adhesive layer is thin, conventional finite elements could easily result in the convergence problem, and the finite element model with the cohesive zone model is applied to solve this problem [16]. It is assumed that the interface of steel and CFRP are bonded well, and the destruction of adhesive layer occurs only in the interior layer.

The finite element model of CFRP strengthened steel plate is shown in fig.2. The model is build by half of the plate due to the symmetry of the geometry and boundary conditions. The steel plate is $3 \mathrm{~mm}$ thickness and $40 \mathrm{~mm}$ width. It has the middle central crack about $10 \mathrm{~mm}$ length. 10 layers of CFRP are pasted on both sides of the steel plate, and each layer is $0.15 \mathrm{~mm}$ thickness. The steel plates and the CFRP laminates are built by using four-node reduced integration quadrilateral shell elements (S4R), and the CFRP mesh is corresponding to the steel plate mesh. The adhesive layer is built by using eight-node cohesive element (COH3D8), with the common nodes of CFRP and the steel plate at the top and bottom surfaces respectively. Three translational DOFs are constrained at the left end nodes, and the Y- direction symmetry constraints are imposed at the below nodes, while the uniform load is applied at the right end nodes.

It is well recognized that the crack-tip modeling is not readily done in a finite element simulation because a divergence problem takes place with refining elements in the vicinity of a crack-tip [17]. The quarter-point node modeling technique can effectively resolve such a challenge [18]. Fig.3 depicts the local finite element model of crack-tip. The crack-tip can be simplified as a small circular arc. In order to accurately calculate the stress intensity factor at crack-tip, the element of crack-tip should be used with SWEEP mesh, with at least 10 elements on a semi-circle.

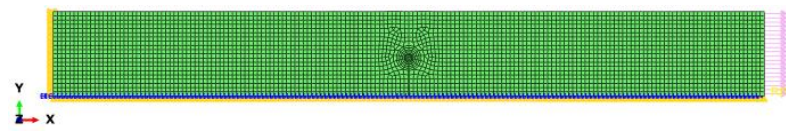

Fig.2 Finite element model of the steel plate strengthened by CFRP

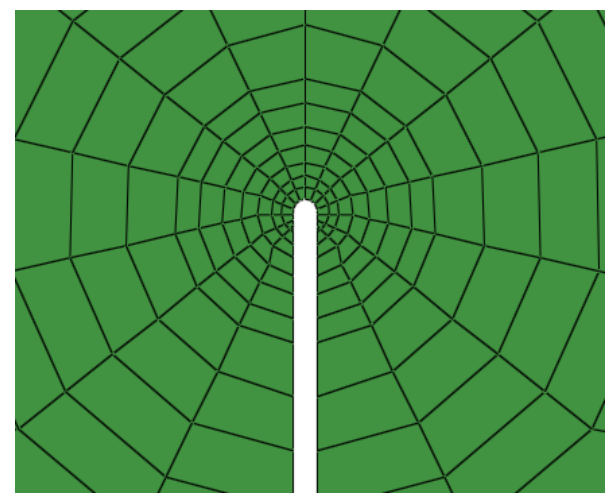

Fig.3 The finite element model of crack plate specimen

The steel material used in the tests is S30400. It is obtained from tensile tests that an average yield stress is $309.5 \mathrm{MPa}$. Besides, an average ultimate tensile strength is 584.3 $\mathrm{MPa}$, and an average Young's modulus is 208.4 GPa.

The CFRP material used in the tests is CUDP- H150/T700-E7 which is one of prepreg CFRP. According to the manufacturer's data sheet, CFRP has a Young's modulus of 120 $\mathrm{GPa}$, an ultimate tensile strength of $2000 \mathrm{MPa}$, 
and a thickness of $0.15 \mathrm{~mm}$ for each ply. It's flexible and can be applied via wet layup to curved structural surfaces.

The epoxy resin used in the bonding of CFRP and steel is Sikadur-330. The thickness between CFRP and steel plates is $0.3 \mathrm{~mm}$. According to the manufacturer's data sheet, the property of adhesive is shown in Table 1.

Table 1 the property of adhesive

\begin{tabular}{ccccccc}
\hline $\begin{array}{c}\text { adhe } \\
\text { sive }\end{array}$ & $\begin{array}{c}\text { tensil } \\
\text { e } \\
\text { stren } \\
\text { gth/M } \\
\mathbf{P a}\end{array}$ & $\begin{array}{c}\text { shear } \\
\text { stren } \\
\text { gth/M } \\
\mathbf{P a}\end{array}$ & $\begin{array}{c}\text { modul } \\
\text { us of } \\
\text { elastic } \\
\text { ity/M } \\
\mathbf{P a}\end{array}$ & $\begin{array}{c}\text { shear } \\
\text { modu } \\
\text { lus/M } \\
\mathbf{P a}\end{array}$ & $\begin{array}{c}\text { norm } \\
\text { al } \\
\text { fractu } \\
\text { re } \\
\text { energ }\end{array}$ & $\begin{array}{c}\text { shear } \\
\text { fractu } \\
\text { re } \\
\text { energ } \\
\mathbf{y} / \mathbf{N} / \mathbf{m} \\
\mathbf{m}\end{array}$ \\
& & & & & $\begin{array}{c}\mathbf{y} / \mathbf{N} / \mathbf{m} \\
\mathbf{m}\end{array}$ & \\
\hline $\begin{array}{c}\text { Sika } \\
\text { dur-3 }\end{array}$ & 20 & 15 & 3000 & 1154 & 0.3 & 0.52 \\
30 & & & & & & \\
\hline
\end{tabular}

\subsection{Verify finite element model}

To validate the finite element model, the stress intensity factor value of bare cracked steel plates, calculated by the finite element model, is compared with the stress intensity factor value calculated by the analytic method. The cracked steel plate is $3 \mathrm{~mm}$ thickness and $40 \mathrm{~mm}$ width. It has the middle central crack about $10 \mathrm{~mm}$ length. The stress amplitude at the right end nodes is $180 \mathrm{MPa}$. The stress intensity factor value of analytical method using by Eq. (5) [15] is $732 \mathrm{MPa} \mathrm{mm}{ }^{0.5}$ and the stress intensity factor value calculating by finite element model was $756 \mathrm{MPa} \mathrm{mm}^{0.5}$. In addition, the relative error of both methods is $3.2 \%$. Therefore, it verifies that the finite element model is correct and accurate.

$$
\Delta K_{I}=\Delta \sigma \sqrt{\pi a / 2}\left(1-0.25 \zeta^{2}+0.06 \zeta^{4}\right) \sqrt{\sec (\pi \zeta / 2)}
$$

Where $\Delta \sigma$ is the remote uniform stress amplitude, $\zeta=w / a$, and $w$ is half width of the steel plate.

\subsection{Analysis of the calculation results}

The steel plate is $3 \mathrm{~mm}$ thickness and $40 \mathrm{~mm}$ width. It has the middle central crack about $10 \mathrm{~mm}$ length. 10 layers of CFRP are pasted on both sides of the steel plate, and each layer is $0.15 \mathrm{~mm}$ thickness. The stress amplitude at the right end nodes is 220MPa. Fig.4 depicts comparison of Misses stress between bare steel plate and CFRP strengthened steel plate. For the bare cracked steel plate, the stress is uniformly distributed away from the crack-tip. The stress concentration is at the crack-tip, and the uniform distribution stress is $210 \sim 240 \mathrm{MPa}$. For the CFRP strengthened steel plate, the stress distribution trend is the same as the bare steel plate, and the uniform distribution stress, away from the crack tip, is $130 \sim 150 \mathrm{MPa}$. Therefore, the overall stress is significantly reduced compared to the bare steel plate.
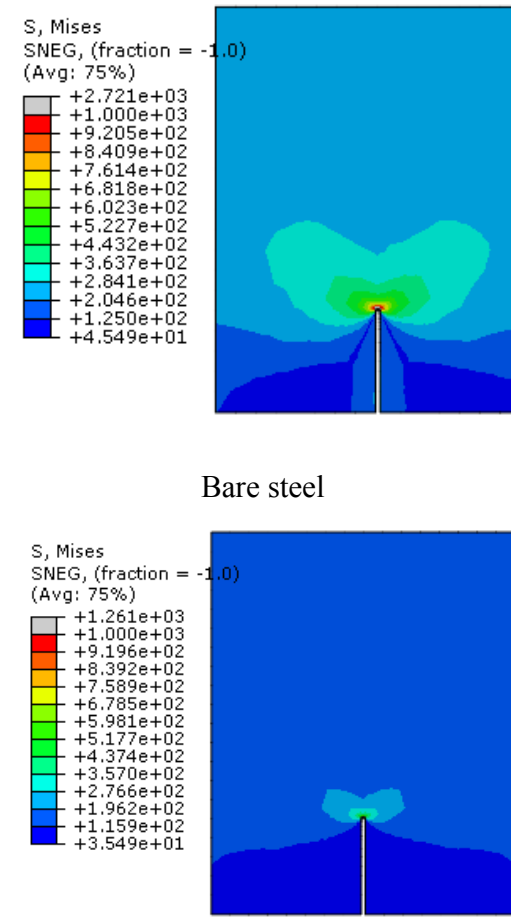

CFRP strengthened steel

Fig.4 Comparison of Misses stress between bare steel and CFRP strengthened steel

Under the same load conditions, the longitudinal stress of CFRP is shown in fig.5. It 
can be found that most of the stress on CFRP is more evenly distributed, but the stress increases rapidly above the crack-tip. It's because the crack reduces the cross-section of steel sheet. The maximum stress of CFRP is $136.8 \mathrm{MPa}$.

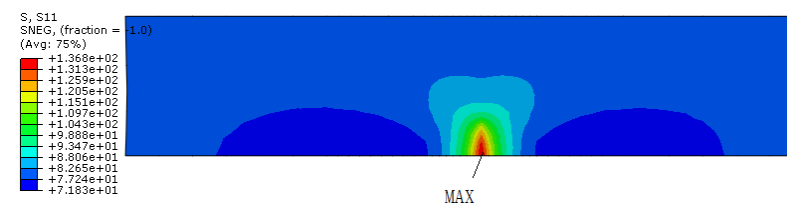

Fig.5 The longitudinal stress of CFRP at crack length $10 \mathrm{~mm}$

When the crack length is $10 \mathrm{~mm}$, the relationship between the crack-tip stress intensity factor and the remote stress is shown in fig.6. The crack-tip stress intensity factor of the bare steel plate is a linear relation with the remote stress amplitude, and the size of stress intensity factor increases as the remote stress rising. It is also a linear relation between the crack-tip stress intensity factor of the CFRP-strengthened steel plate and the remote stress. But the stress intensity factor is significantly reduced compared to the bare steel plate, and the stress intensity factor is reduced more with the remote stress increasing.

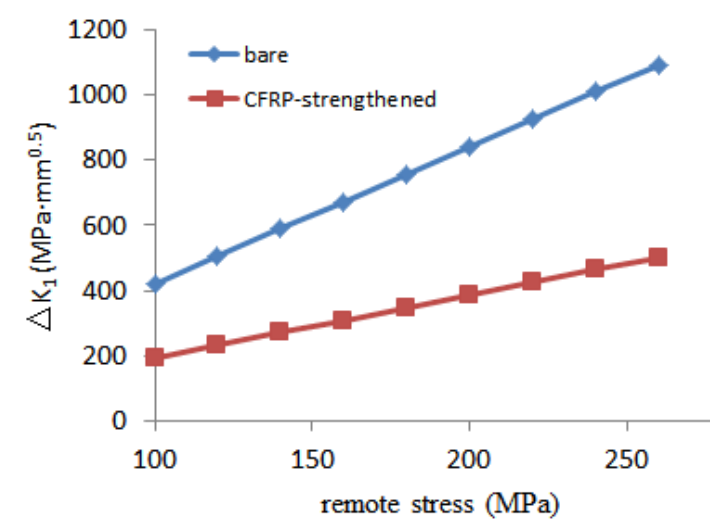

Fig.6 The relation between stress intensity factor and remote stress

When the remote stress is $180 \mathrm{MPa}$, the relationship between the crack-tip stress intensity factor and the crack length is shown in fig.7. It can be seen that the stress intensity factor of crack-tip decreases obviously after
CFRP reinforcement. For example, when the crack length is $10 \mathrm{~mm}$, the stress intensity

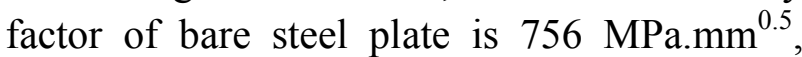
while the stress intensity factor of CFRP-strengthened steel plate is 348 MPa. $\mathrm{mm}^{0.5}$. With the increase of crack length, stress intensity factor reduces more.

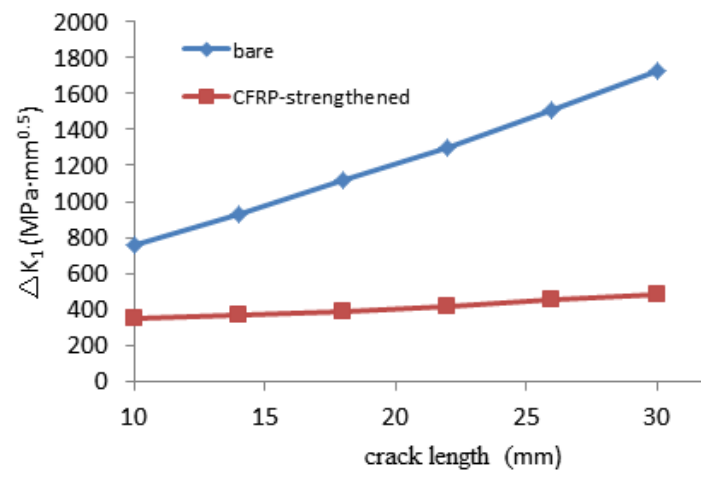

Fig.7 The relation between stress intensity factor and crack length

\section{Fatigue test}

According to Eq. (2), to predict the fatigue life of CFRP-strengthened cracked steel plate, material constants $C$ and $n$ are important parameters. They can be obtained using Eq. (1) by the following experimental data and $\Delta K_{I}$ calculated by finite element method. In addition, the experiment fatigue life is compared with the prediction fatigue life to verify the accurate of prediction fatigue life.

\subsection{Test program}

In order to obtain material constants $C$ and $n$ in Eq. (1) and verify the prediction of fatigue life for crack, fatigue tests of bare cracked steel plate and CFRP-strengthened cracked steel plate are illustrated here. According to the standard "metal tensile test at ambient temperature", specimens were designed to be similar to a dumbbell. The specimen dimensions are shown in fig.8. Each specimen has a length of $390 \mathrm{~mm}$ and a thickness of 3 $\mathrm{mm}$. To simulate the initial crack, a crack is made in the middle span of each specimen 
by linear cutting. The length of crack is $10 \mathrm{~mm}$. For CFRP-strengthened cracked steel plate, both sides of the steel plate are pasted 10-layers of CFRP. The width of CFRP is same as steel plate, and each layer of CFRP thickness is 0.15 $\mathrm{mm}$. Each specimen included two different stress amplitude $180 \mathrm{MPa}$ and $260 \mathrm{MPa}$, with stress ratio 0.1 . All the tests were conducted on the high-frequency fatigue testing machine QBG-400. In order to prevent CFRP debonding, the end of CFRP was reinforced by mechanical fixture. The crack length of bare steel plate was observed by using 25 times microscope in the test. Experimental details are demonstrated in table .2 .

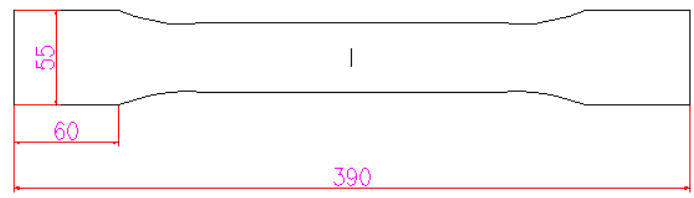

Fig.8 Specimen size

Table 2 The fatigue test of crack plate

\begin{tabular}{|c|c|c|c|c|}
\hline Symbol & Specimen & $\begin{array}{c}\text { Stress } \\
\text { amplitu } \\
\text { de } \\
(\mathrm{MPa})\end{array}$ & $\begin{array}{l}\text { Laye } \\
\text { r no. }\end{array}$ & $\begin{array}{l}\text { Specime } \\
\text { n no. }\end{array}$ \\
\hline $\begin{array}{c}\text { Steel-18 } \\
0\end{array}$ & $\begin{array}{l}\text { bare cracked } \\
\text { steel plate }\end{array}$ & 180 & no & 2 \\
\hline $\begin{array}{c}\text { CFRP-18 } \\
0\end{array}$ & $\begin{array}{l}\text { CFRP-strengthen } \\
\text { ed cracked steel } \\
\text { plate }\end{array}$ & 180 & 20 & 2 \\
\hline $\begin{array}{c}\text { Steel-26 } \\
0\end{array}$ & $\begin{array}{l}\text { bare cracked } \\
\text { steel plate }\end{array}$ & 260 & no & 2 \\
\hline $\begin{array}{c}\text { CFRP-26 } \\
0\end{array}$ & $\begin{array}{l}\text { CFRP-strengthen } \\
\text { ed cracked steel } \\
\text { plate }\end{array}$ & 260 & 20 & 2 \\
\hline
\end{tabular}

The process of pasting CFRP was designed as follows: (1) In order to remove the oxide layer and pollutants above the steel plate surface and form a certain surface roughness for enhancing the cohesive force of steel and adhesive, we used the sandblasting on the steel plate surface. (2) The surface of steel plate was scrubbed by using alcohol to remove grease and contaminants. (3) Adhesive $\mathrm{A}$ and adhesive B of Sikadur-330 were mixed according to certain proportion and blended well for about 5 minutes. (4) The mixed adhesive was painted evenly over the surface of the steel plate with a special brush, and then CFRP was pasted to the top of adhesive, whose thickness was about $0.3 \mathrm{~mm}$. (5) Specimens were placed more than half a day at ambient temperature, and then solidified in the incubator with the temperature of $45{ }^{\circ} \mathrm{C}$ and duration of 90 minutes.

\subsection{Analysis of experimental results}

Fatigue damages of bare cracked steel plate and CFRP-strengthened cracked steel plate are shown in fig.9. CFRP-strengthened plate constantly emitted a "creak" sound during the test. After the steel plate was completely broken, CFRP can still bear the load. Fig.9 exhibits the steel plate damage after removing CFRP. The crack source of bare cracked steel plate is located at the crack-tip, and is gradually extended to both sides of plate.

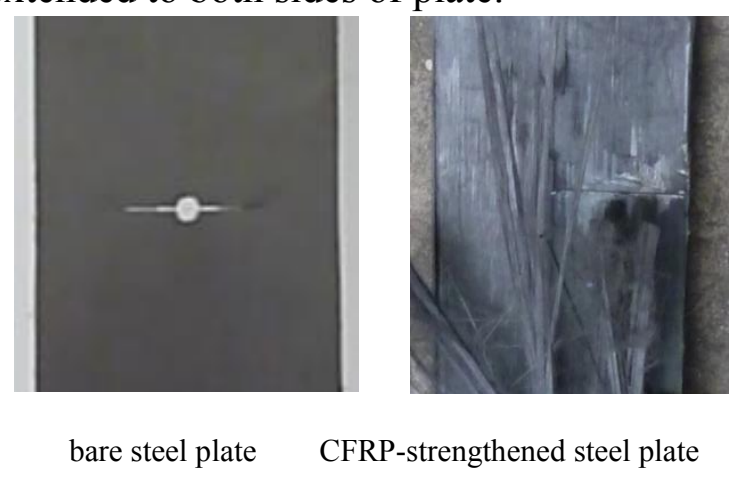

Fig.9 The fatigue damage of specimen

Table 3 shows the experiment fatigue life of specimens. With the increase of nominal stress amplitude, the fatigue life of bare cracked steel plate and CFRP-strengthened cracked steel plate are reduced. When the nominal stress amplitude is $180 \mathrm{MPa}$, the experimental fatigue life of bare cracked steel plate is 57.01 thousand times, while the experimental fatigue life of CFRP-strengthened cracked steel is 1.56 million times. When the nominal stress amplitude is $260 \mathrm{MPa}$, the experimental fatigue life of bare cracked steel plate is 5.91 thousand times, while the experimental fatigue life of 
CFRP-strengthened cracked steel is 101.30 thousand times. So it can be found that CFRP-strengthening can effectively improve the fatigue life of the cracked steel plate.

Table 3 Experiment fatigue life of specimens (thousand times)

\begin{tabular}{ccccc}
\hline $\begin{array}{c}\text { Specime } \\
\text { n }\end{array}$ & $\begin{array}{c}\text { Steel-18 } \\
\mathbf{0}\end{array}$ & $\begin{array}{c}\text { Steel-26 } \\
\mathbf{0}\end{array}$ & $\begin{array}{c}\text { CFRP-18 } \\
\mathbf{0}\end{array}$ & $\begin{array}{c}\text { CFRP-26 } \\
\mathbf{0}\end{array}$ \\
\hline Test 1 & 55.12 & 5.28 & 1530.36 & 99.63 \\
Test 2 & 58.89 & 6.53 & 1579.87 & 102.97 \\
Test & 57.01 & 5.91 & 1555.12 & 101.30 \\
average & & & & \\
\hline
\end{tabular}

\section{Fatigue parameters and fatigue life prediction}

\subsection{Calculation for fatigue parameters $C$ and $n$}

The crack length and fatigue life of cracked steel plate are measured through the fatigue experiment. Assuming the nominal stress amplitude is $180 \mathrm{MPa}$, the relation between the crack length and the fatigue life about bare cracked steel plate is shown in Fig.10. The crack length is increased with the fatigue life increases. The crack length grows slowly when the fatigue life is small, but it grows faster when the fatigue life is longer.

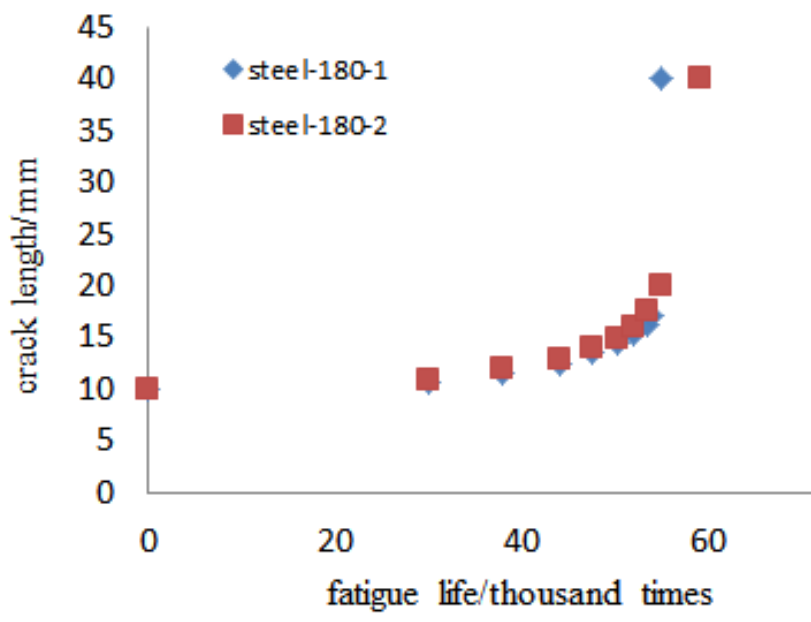

Fig.10 The crack length versus the fatigue life about bare cracked steel plate

According to the experimental data in Fig.10, the crack growth rate can be calculated by using the secant method. Taking two adjacent experimental data recorded as $\left[a_{i}, N_{i}\right]$ and $\left[a_{i+1}, N_{i+1}\right]$, the crack growth rate between the two experimental data can be represented:

$$
\left(\frac{d a}{d N}\right)_{i}=\frac{a_{i+1}-a_{i}}{N_{i+1}-N_{i}}
$$

Where $a_{i}$ is crack length and $N_{i}$ is fatigue life. When the nominal stress is $180 \mathrm{MPa}$, the crack growth rate of bare cracked steel plate can be calculated by Eq.6. The Fig.11 shows the crack growth rate is increased with the crack length growing. The relative error of the two specimens' crack growth rate is smaller when the crack length is smaller, but it is larger when the crack length is larger.

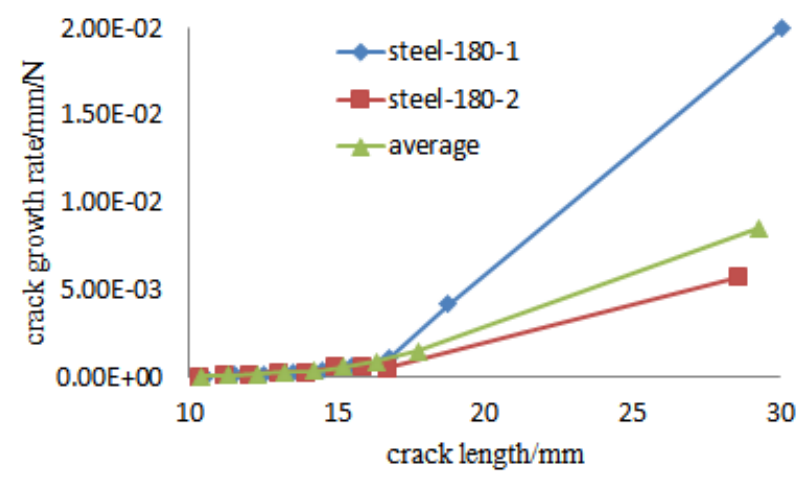

Fig.11 Relation between crack growth rate and crack length

The stress intensity factor amplitude corresponding to $a_{i}$ is calculated by using finite element model under the same load conditions. As is shown in table 4, it lists crack growth rate, the stress intensity factor amplitude and their logarithmic of the different crack length.

Table 4 Fatigue performance of bare cracked steel plate

\begin{tabular}{ccccc}
\hline $\begin{array}{c}\text { crack } \\
\text { length/m }\end{array}$ & $\begin{array}{c}\text { Srowth } \\
\text { rate } \\
\text { m }\end{array}$ & $\begin{array}{c}\text { SIF } \\
\text { amplitude } \\
\text { /MPa·mmo }\end{array}$ & $\begin{array}{c}\lg (\mathbf{d a} / \mathbf{d N} \\
\mathbf{m m}\end{array}$ & $\begin{array}{c}\lg (\boldsymbol{\Delta} \mathbf{K I} \\
\mathbf{5}\end{array}$ \\
\hline 10.43 & $2.83 \mathrm{E}-05$ & 776.66 & -10.47 & 6.65 \\
11.33 & $1.19 \mathrm{E}-04$ & 820.40 & -9.04 & 6.71 \\
12.28 & $1.58 \mathrm{E}-04$ & 866.57 & -8.75 & 6.76 \\
13.25 & $2.86 \mathrm{E}-04$ & 913.95 & -8.16 & 6.82 \\
14.23 & $3.39 \mathrm{E}-04$ & 961.34 & -7.99 & 6.87 \\
15.20 & $5.88 \mathrm{E}-04$ & 1008.72 & -7.44 & 6.92 \\
16.30 & $8.57 \mathrm{E}-04$ & 1062.18 & -7.06 & 6.97 \\
17.73 & $1.50 \mathrm{E}-03$ & 1131.44 & -6.50 & 7.03 \\
29.28 & $8.58 \mathrm{E}-03$ & 1692.77 & -4.76 & 7.43 \\
\hline
\end{tabular}


Taking natural logarithms on both sides of

Eq.1:

$$
\lg (d a / d N)=\lg C+n \lg \left(\Delta K_{I}\right)
$$

Generally, $C$ and $n$ in Eq. 7 are considered as material constants, which are only related to the material properties and loading conditions. Eq.7 shows $\lg (d a / d N)$ and $\lg \left(\Delta K_{I}\right)$ are linear relationship. Parameters $C$ and $n$ can be obtained by the linear least-squares according to the data in table 4. Thus, using our experimental data, the parameter $C$ is $0.82 \times 10^{-14}$, and the parameter $n$ is 3.525 . The cracked steel plate's fitting curve between $\lg (d a / d N)$ and $\lg \left(\Delta K_{I}\right)$ is shown in Fig.12 and it is consistent with the data according to the figure.

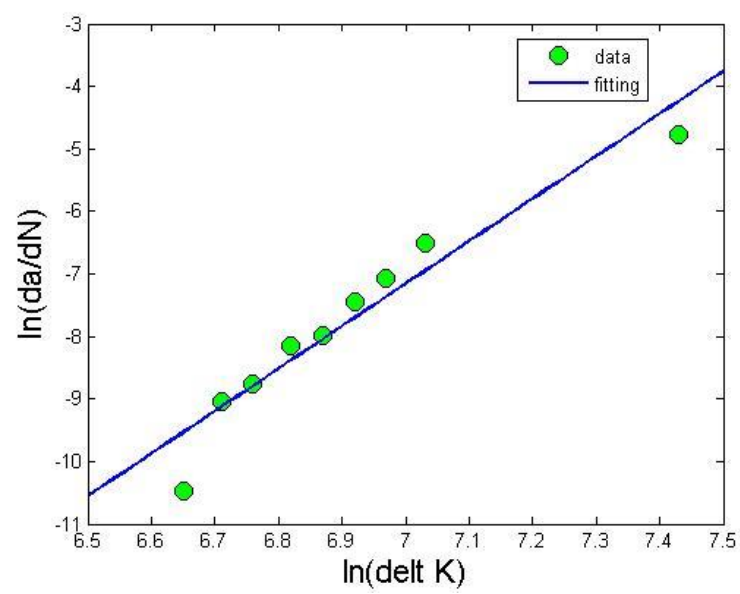

Fig.12 Cracked steel plate's fitting curve between $\lg (d a / d N)$ and $\lg \left(\Delta K_{I}\right)$

\subsection{Fatigue life prediction and validation}

If the whole crack propagation length $\Delta a$ of the cracked steel plate and CFRP strengthened cracked steel plate are divided into a number of micro-increment $\Delta a_{i}$, and assuming that the stress intensity factor amplitude of crack tip is unchanged in the range of the micro-increment, we can calculate stress intensity factor amplitudes $\Delta K_{I \text { (i) }}$ of two kinds of specimens with different crack length $a_{i}$ by the finite element model. The results are shown in table 5 ,

Table 5 Stress intensity factor amplitudes of specimens with different crack length

\begin{tabular}{cccc}
\hline $\begin{array}{c}\text { crack } \\
\text { length/m } \\
\text { m }\end{array}$ & $\begin{array}{c}\text { cfrp-180 } \\
\text { /MPa·mm0.5 }\end{array}$ & $\begin{array}{c}\text { steel-260/ } \\
\text { MPa·mm0.5 }\end{array}$ & $\begin{array}{c}\text { cfrp-260 } \\
\text { /MPa·mm0.5 }\end{array}$ \\
\hline 11 & 355 & 1166 & 510 \\
12 & 362 & 1239 & 518 \\
13 & 369 & 1313 & 526 \\
14 & 375 & 1386 & 534 \\
15 & 382 & 1460 & 543 \\
16 & 389 & 1533 & 551 \\
17 & 396 & 1607 & 559 \\
18 & 403 & 1680 & 567 \\
19 & 410 & 1754 & 575 \\
20 & 417 & 1827 & 583 \\
21 & 423 & 1901 & 591 \\
22 & 430 & 1974 & 599 \\
23 & 437 & 2048 & 607 \\
24 & 444 & 2121 & 615 \\
25 & 451 & 2195 & 624 \\
26 & 458 & 2268 & 632 \\
27 & 464 & 2342 & 640 \\
28 & 471 & 2415 & 648 \\
29 & 478 & 2489 & 656 \\
\hline & & &
\end{tabular}

If assuming that the stress intensity factor amplitude of crack tip is unchanged in the range of the micro-increment, Eq. 2 can be expressed as:

$$
N=\sum_{i=1}^{m} \frac{\Delta a_{i}}{C\left[\Delta K_{I(i)}\right]^{n}}
$$

The fatigue life of specimen can be predicted according to the Eq. 8 and table 5, and the results are shown in Fig.13. It's shown that the fatigue life of specimen CFRP-180 is much longer than specimen CFRP-260 and steel-260. Under the same crack increment, the fatigue life increases smaller with the crack propagation. For example, the specimen CFRP-180's increment fatigue life is 99.3 thousand times when its crack length is from $10 \mathrm{~mm}$ to $11 \mathrm{~mm}$, and the increment fatigue life 
is 40.9 thousand times when the crack length is from $25 \mathrm{~mm}$ to $26 \mathrm{~mm}$.

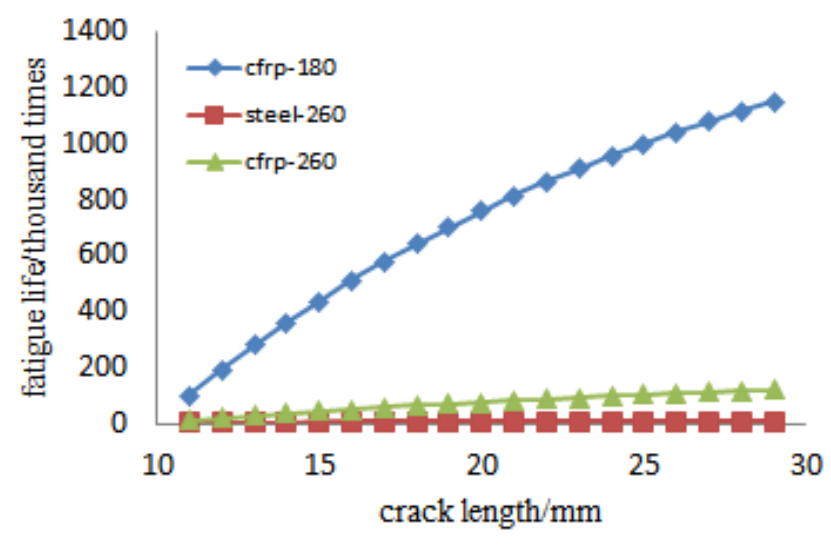

Fig.13 Prediction fatigue life of specimens

Table 6 shows the prediction and experiment fatigue life of specimens. It's shown that the prediction fatigue life of all specimens are consistent with the experimental fatigue life, so the fatigue life of CFRP-strengthened cracked steel plate can be accurately predicted by the calculation method based on finite element model.

Table 6 The prediction and experiment fatigue life of specimens

\begin{tabular}{cccc}
\hline specimens & \multicolumn{2}{c}{ fatigue life/ thousand times } & relative \\
\cline { 2 - 3 } & experiment & prediction & error/\% \\
\hline steel-180 & 57.1 & 51.3 & 10.2 \\
steel-260 & 5.5 & 8.7 & 58.2 \\
CFRP-180 & 1555.7 & 1150.1 & 26.1 \\
CFRP-260 & 101.5 & 119.8 & 18.0 \\
\hline
\end{tabular}

\section{Conclusions}

This paper has established the finite element model of CFRP-strengthened cracked steel plate by using the cohesive zone model. With the finite element model, stress intensity factor of the crack has been calculated. Then, four groups of fatigue test on cracked steel plate have been conducted. Finally, it investigates the influences of CFRP thickness, CFRP length and CFRP width on the stress intensity factor by using the finite element model. The conclusions from this study are drawn:
The finite element model based on cohesive zone model can accurately calculate the stress intensity factor of crack-tip. The relative error about the stress intensity factor value of bare cracked steel plates, calculated by the finite element model and analytical method, is $3.2 \%$.

The values of material constants $C$ and $n$ in Eq. (1) are obtained based on our experimental data and stress intensity factor calculated by the finite element model. The parameter $C$ is $0.82 \times 10^{-14}$, and the parameter $n$ is 3.525 .

The prediction of fatigue life calculated by the finite element model and the Paris function is consistent with the experimental fatigue life. The relative error of fatigue life for specimen CFRP-260 by both experiment and prediction methods is $18.0 \%$.

It is necessary to design the reasonable CFRP width, CFRP length and CFRP thickness according to practical requirement.

The project is supported by the National Natural Science Foundation of China (Grant No U1737112) and Chinese Postdoctoral Station of Yihua Life Science and Technology Co., Ltd ( No. 201141).

\section{References}

[1] Schijve J. Fatigue of structures and materials in the 20th century and the state of the art. Int J Fatigue 2003;25:679-23.

[2] Cadei JM, Stratford TJ, Hollaway LC, Duckett WG. Strengthening metallic structures using externally bonded fibre-reinforced polymers. London: CIRIA, Publication C595; 2004.

[3] Zhao X-L, Zhang L. State-of-the-art review on FRP strengthened steel structures. Eng Struct 2007;29:1808-23.

[4] Harries KA, El-Tawil S. Review of steel-FRP composite structural systems. In:Proceedings of the 5th international conference on composite construction,Colorado, USA (CD-ROM); 2008. 
[5] Agarwal A, Foster SJ, Hamed E, Ng TS. Influence of freeze-thaw cycling on the bond strength of steel-FRP lap joints. Compos B 2014;60:178-85.

[6] Zhou H, Attard TL, Wang Y, Wang J-A, Ren F. Rehabilitation of notch damaged steel beams using a carbon fiber reinforced hybrid polymeric-matrix composite. Compos Struct 2013;106:690-12.

[7] Sebastian W, Zhang C. Observations from testing of indeterminate FRP-plated steel beams on flexible supports. Compos B 2013;45:200-14.

[8] Jones Sean C,Civjan Scott A. Application of fiber reinforced polymer overlays to extend steel fatigue life. Journal of Composites for Construction 2003,7:331-8.

[9] Hui Jiao, FidelisMashiri, Xiao-LingZhao. A comparative study on fatigue behaviour of steel beams retrofitted with welding, pultruded CFRP plates and wet layup CFRP sheets. Thin-Walled Structures 2012;59: 144-8.

[10] Amer Hmidan, Yail J. Kim, Siamak Yazdani. Correction factors for stress intensity of CFRP-strengthened wide-flange steel beams with various crack configurations. Construction and Building Materials 2014; 70: 522-8.

[11] Zhang Shukuan,Huang Peiyan,Zhao Chuanyu. Numerical analysis of stress intensity factor of surface crack in steel plate strengthened with CFL under bending load. Journal of South China University of Technology 2014; 40:162-6.

[12] Yang Fubiao, Xiao Jiayu, Jiang Dazhi. Fatigue failure properties of pre-cracked aluminum alloy plates one-side-bonded With Composite Patches. Surface Engineering of China 2006; 19:210-5.

[13] $\mathrm{H}$ Minnebo ,Three-dimensional integration strategies of singular functions introduced by the XFEM in the LEFM. International Journal for Numerical Methods in Engineering 2012; 92:1117-21.

[14] Paris P C, Erdogan F. A critical analysis of crack propagation laws ,. Journal of Basic Engineering. 1963;85: 528 6.

[15] Chen Chuanyao. Fatigue and fracture. Wuhan:Huazhong University of Science and Technology Press; 2002.
[16] J.G. Teng, D. Fernando, T. Yu. Finite element modelling of debonding failures in steel beams flexurally strengthened with CFRP laminates. Engineering Structures 2015;1:213-12

[17] Chan SK, Tuba IS, Wilson WK. On the finite method in linear fracture mechanics. Eng Fract Mech 1970;2:1-17.

[18] Henshell RD, Shaw KG. Crack-tip finite elements are unnecessary. Int J Numer Meth Eng 1975;9:495-12. 